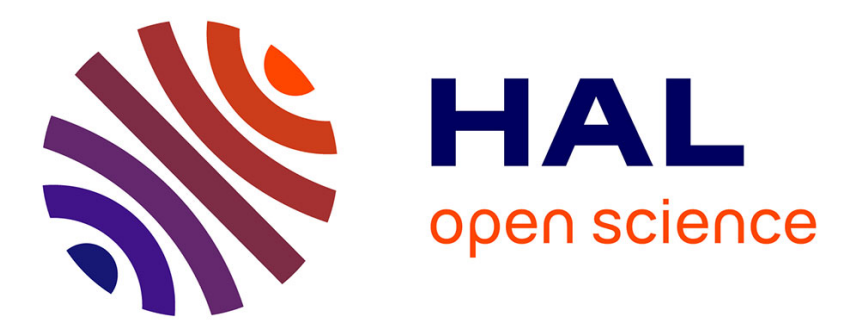

\title{
Towards Co-designing with Users: A Mixed Reality Tool for Kansei Engineering
}

\author{
Pierre-Antoine Arrighi, Santosh Maurya, Céline Mougenot
}

\section{To cite this version:}

Pierre-Antoine Arrighi, Santosh Maurya, Céline Mougenot. Towards Co-designing with Users: A Mixed Reality Tool for Kansei Engineering. 12th IFIP International Conference on Product Lifecycle Management (PLM), Oct 2015, Doha, Qatar. pp.751-760, 10.1007/978-3-319-33111-9_68 . hal01377503

\section{HAL Id: hal-01377503 \\ https://hal.inria.fr/hal-01377503}

Submitted on 7 Oct 2016

HAL is a multi-disciplinary open access archive for the deposit and dissemination of scientific research documents, whether they are published or not. The documents may come from teaching and research institutions in France or abroad, or from public or private research centers.
L'archive ouverte pluridisciplinaire HAL, est destinée au dépôt et à la diffusion de documents scientifiques de niveau recherche, publiés ou non, émanant des établissements d'enseignement et de recherche français ou étrangers, des laboratoires publics ou privés. 


\title{
Towards Co-designing with Users: A Mixed Reality Tool for Kansei Engineering
}

\author{
Pierre-Antoine Arrighi, Santosh Maurya, Céline Mougenot \\ Department of Mechanical Sciences and Engineering \\ Tokyo Institute of Technology
}

\begin{abstract}
Some costly and complex technical products, such as walking assistance devices, require ad-hoc design processes to address the very specific needs of each user. However, the depiction of customer/user requirements in the early stage of design stands difficult due to their subjective nature and the separation between the user and the designer. To bridge these gaps, we introduce the definition of a new modular digital toolbox based upon mixed reality system and kansei engineering techniques. The hardware consists in modular Tangible User Interfaces (TUIs), custom made by $3 \mathrm{D}$ printing and powered by a 3D game engine. The interactive content is displayed in mixed reality, simultaneously to the user and the designer. Kansei data are collected through questionnaires and psychophysical measurements, during multiple collaboration phases. The modularity of the system allows the evaluation of various TUIs, 3D content behaviours and the best fitting type of display.
\end{abstract}

Keywords: customer requirements, collaborative design, mixed reality, kansei engineering, tangible user interfaces.

\section{Introduction and motivation}

\subsection{Supporting mobility requires the design of complex mechanical products}

We are currently in the midst of a profound demographic shift. The aging of the population in developed countries is a groundswell, due to a slowing birth rate and an increasing life expectancy. In Japan for example, the share of the population over 60 was $8 \%$ in $1950,10 \%$ in 2000 , and is expected to reach $21 \%$ in 2050 . In a near future, one out of four people will be over 65 [1]. Among all challenges raised by the aging of the population, mobility appears as one of the most pressing issues [2]. The prevalence of mobility impairments increases with age, i.e. one in ten for people in their fifties, up to one in two for those in their eighties. Losing complete or partial mobility affects not only the ability to walk, but also the ability to perform daily tasks, which is a major determinant in quality of life and causes dependence on others [3]. To address walking disabilities, "one fits all" solutions are the most common. As an example, wheelchairs are often recommended to patients with mobility impairment conditions caused by lower limbs disability. Although safe and easy-to-use, they also have many disadvantages, e.g. they limit activities due to their large footprint and make it complicated to perform basic daily tasks due to the limited reach they offer. 
Wheelchairs also tend to limit the visibility field of their users, making it difficult both to see and to be seen.

In order to overcome most of these limitations, efforts have been put to offer users an upright posture through more sophisticated products. For instance, robotic exoskeletal apparatuses [3] such as powered suit HAL [4], Ekso [5] or Vanderbilt Powered Orthosis [4, 6]. Some of them may require using an additional remote walker [7]. However, such products tend to be complicated and expensive, both to design and operate.

\subsection{New design tools for a better fit to user requirements}

For designers, one way of simplifying their products is to take into account the fact that many people with walking-impairment have a valid upper body. Therefore, the focus of research has shifted towards apparatuses capable of autonomously supporting users by leveraging their remaining upper mobility and led to the design of simpler and less expensive devices like illustrated in Fig. 1 (c) $[8,9]$. Due to space limitations, we are not able to give more details about our use case.

(a)

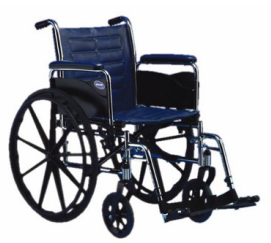

(b)

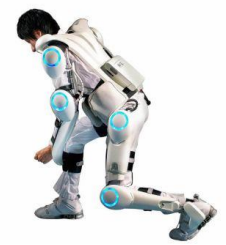

(c)

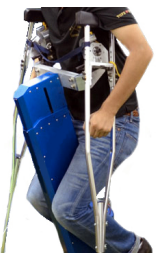

Fig. 1. Illustration of assistance devices for walking impaired people. (a) bimanual rear-wheel driven folding wheelchair, (b) Exoskeleton (HAL) [4], (c) Walking assist machine using crutches (WAMC) [8].

At the same time, quality of living and comfort has taken priority over simple functional solutions for the users. In projects involving medical assistance devices, it is of paramount importance to take into account the detailed condition of the user and focus on ergonomics, usability, user acceptance, body metrics and adequacy to the user's feeling [4]. Focusing on such items can result in safer products and faster learning curves for the user [10]. These elements are key drivers of the final product properties and should be considered from the very early design stages. They are all related to what is called the user 'kansei' [11]. Kansei is a Japanese term that can be translated as "emotion" or "affect" and encompasses all aforementioned items. It is deeply linked to the customer requirements; as kansei engineered products tend to increase the satisfaction of their users. However, incorporating the kansei requirements at early design steps poses a major challenge because designers need to take into account both psychological and physiological user requirements simultaneously.

Hence our research question: How to improve the design process of products that require a good fit with user requirements, such as walking assistance devices? 
Early user involvement in the design process has several advantages. The main benefits are an increased access to and understanding of the user's needs, experiences, and ideas; improvements in medical devices designs and user interfaces; and an increase in the functionality, usability, and quality of these devices. In particular, the involvement of users is crucial at each stage of the product development cycle to leverage in a cumulative way their contributions and thus to maximize their effects [12]. One good option for integration through collaboration between user and designer during the design process is the use of common "tools". The tools are able to trace the interactions between users, they support the design process itself and produce representations of the concept, from early steps to final completion of the physical object. The representations are key for collecting one's kansei [11] and can be used as boundary objects [13]. The tools facilitate exchange between the designers and the people who will experience the products [14].

Therefore our objective is to invent a new tool to support the integration of the user and their kansei requirements inside the design process of medical assisting walking devices. For an optimal integration and compatibility into the current digital design process of such products we concentrated our research on Computer Aided Design (CAD) tools.

Hypothesis: With an earlier involvement of the user in the design process it is possible to design better products. This could be achieved with a new tool that allows the user to participate in the early stages of the design process the mobilization of his kansei data can leverage the design process for better products.

\section{Existing digital design tools and methods}

\subsection{CAD strength and weakness in early design stage}

The design of most complicated devices requires simulations, analysis, and optimisation conducted with CAD tools. As a consequence they are essential when dealing with the design of medical assistance devices. However, the participation of users during the design process and the integration of kansei engineering from the early steps could be improved.

Because of the number of functions they support the CAD tools require a long training with steep learning curves. The designers who use them only become experts after years of mechanical education. They require good perceptive and imaginative skills along with a technical educational background [15]. Their complexity notably lies in their human machine interfaces, which impair collaboration and direct interaction with the CAD objects [16]. The keyboard and mouse widely dominate work environments. If they are very capable in terms of performance in expert's hands they however might not be easy to handle by elderly people who are sometimes unfamiliar with the technology. They also require dexterity and precision, which may be an issue in the case of physical impairment.

The compatibility of CAD tools with early design stages, when kansei requirements must be generated and collected, could also be improved. The conceptual design phase is critical for involving collaboration between designers and 
users and integrating the specific requirements of the latter [17]. As a consequence, the user is often requested to give feedbacks about already well-developed representations (e.g. CAD models), which are difficult to interact with. Recently, new types of Computer-aided Design interfaces can produce realistic representations of the product being designed for a reasonable cost. The Fig. 2 illustrates the limited feedbacks and perception clues for a user.

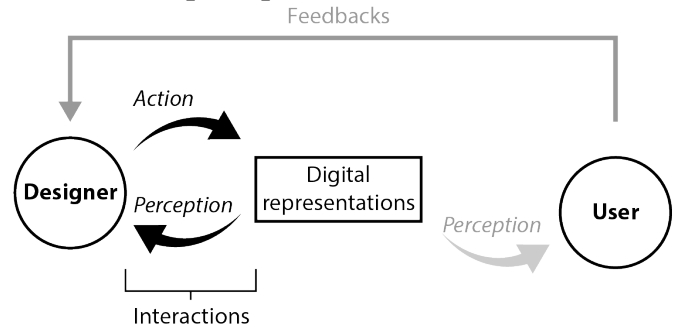

Fig. 2. Integration of the user in the design process with CAD tools.

Mixed Reality (MR) is defined as a particular subset of Virtual Reality (VR), related technologies that involve the merging of real and virtual worlds somewhere along the "virtuality continuum" [18] that spans between completely real environments and completely virtual ones and illustrated in Fig. 3. One of the major advantages of this type of interfaces is the possibility of leveraging the real world with virtual elements (as in augmented reality) or to map virtual elements to real physical objects manipulated by the user (as in augmented virtuality).

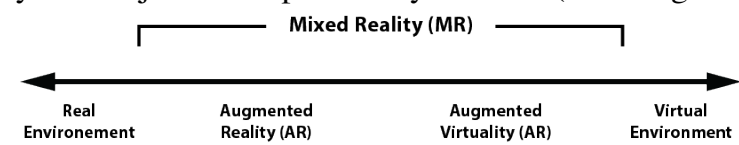

Fig. 3. The "virtuality continuum" as defined in [18].

MR systems can facilitate the integration of user in the design process because they offer an enhanced perception of the future product. The VR technology enables the user to experience the design model with high quality of presence by using the interactive three-dimensional image without making an actual product from the early design stages [19]. They offer shared representations and boundary objects for better communication between designers and users. Boundary objects [13] work to establish a shared context between designers. They can be objects or models are simple or complex representations that can be observed and then used across different functional settings. These representations of the under design object depict or demonstrate current or the possible "form, fit, and function", in other words, fitting to the knowledge of the user. An enhanced perception of the CAD object for the user is illustrated in Fig. 4. 


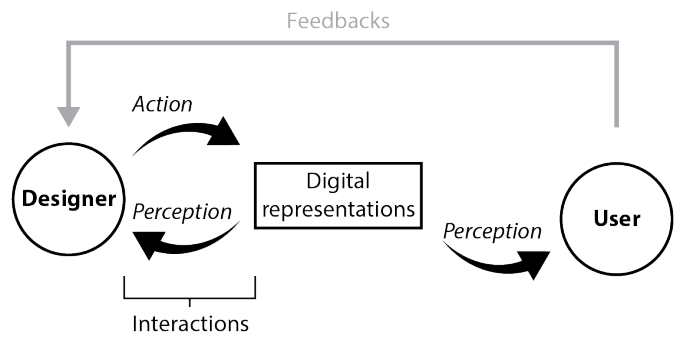

Fig. 4. Integration of the User in the design process with VR CAD tools.

\subsection{Kansei engineering methods for early incorporation of user preference}

Kansei engineering is a technique that can contribute to higher user satisfaction [11]. However, its implementation in real life is difficult, especially when the products to be designed are complex and when the design is done in a lab-based environment, as is it the case for walking assistance devices.

Design engineers have their own tools, processes and methods [20]. In order to capture the user requirements during the medical design solution development, designers usually refer to existing references. However, the methods discussed in the scientific literature can rarely be applied to actual use cases, while current industrial practice may be confidential, and there is little knowledge available about methods and approaches needed to capture the full range of requirements [10]. Designing specific walking assistance devices implies the collection of all the specific requirements from the end user. It is expected from the designers to know the kansei and lifestyle of users and to suggest realistic solutions to improve them [1]. The kansei requirements challenges come on top of the traditional technical challenges, which are already demanding and labour intensive [10].

This leads to the interweaving of several academic fields, i.e. medicine, engineering and social sciences [21]. As a consequence kansei engineering design often imply the integration of dedicated kansei tools and methods in addition to the process $[22,11]$. However this approach consider the user as a source of design information but mostly as an indirect participant. Kansei engineering methods recommends the collection of customer feedbacks at the early design steps for best results. Measurable usability criteria address issues related to the effectiveness, efficiency, safety, utility, learnability and memorability.

We want to mix the advantages of MR (virtual and augmented reality tools with Tangible User Interfaces (TUIs) with kansei engineering techniques. Successful projects have been conducted with the integration of VR and kansei engineering, as schematised in Fig. 5. This technique is called kansei engineering type IV [1]. 


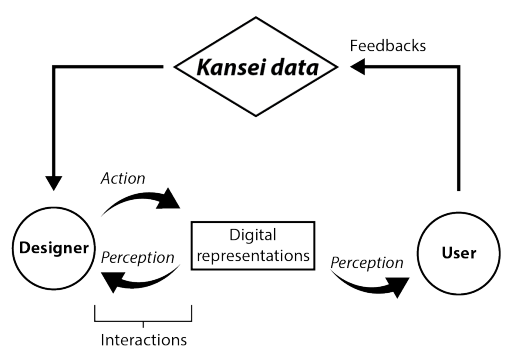

Fig. 5. Integration of the User in the design process with VR CAD tools in kansei engineering type IV [1].

\subsection{Co-design for user early involvement}

Typical digital tools follow a step-by-step process where representations are first shown to the user and then modified by the designer, as illustrated in Fig. 6. This step by step process requires the designer involvement to modify the CAD object after collecting the user's feedbacks.

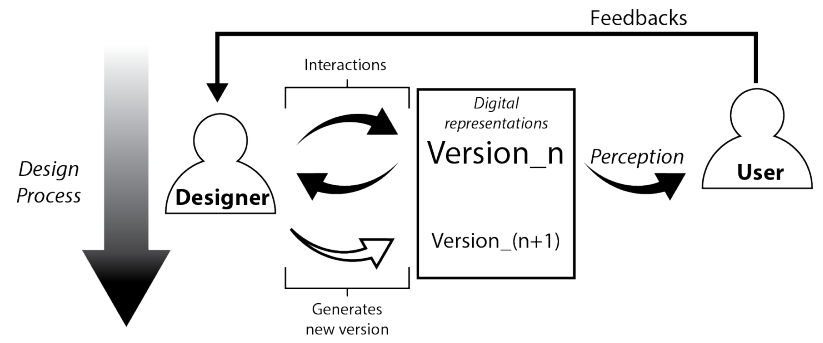

Fig. 6. Flow of representations along the design process.

Collaboration and co-design imply the ability for all participants to be able to modify and interact directly with the representations, as illustrated in Fig. 7. Doing so in a digital environment implies dedicated tools capable of supporting such activities, with specific interfaces. This requirement is even more stringent when dealing with the early design steps.

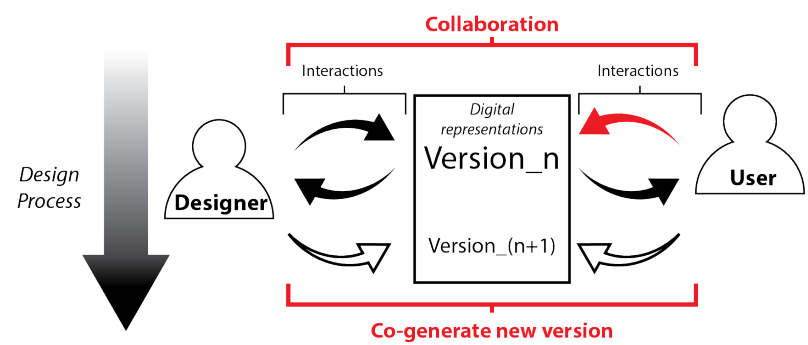

Fig. 7. Flow of representations along a co-design process. 


\section{Definition of a new MR kansei based tool for early co-design}

\subsection{Principles of the tool}

The tool needs to be compatible with the current design process, namely the digital tools the designers are already using and their methods. We will use digital tools and the manipulation of CAD data for a better integration. The system will focus on the initial design steps for the definition of user requirements and during the design iterations and evaluations of digital prototypes.

The tool needs to integrate the user in the design process by giving him/her simple interfaces to collaborate actively with the designers. We also need the system to be capable of changing configurations for fitting different users. One of the solutions is to create the interfaces on demand for each use case and ensure their compatibility with the system with a modular architecture.

The tool needs to be kansei-engineering compliant. A kansei engineering process requires being written in addition to the already existing design process, and capable of leveraging the capacity for the designers to capture kansei data through interaction/collaboration phases with the user. The Fig. 8 illustrate this workflow.

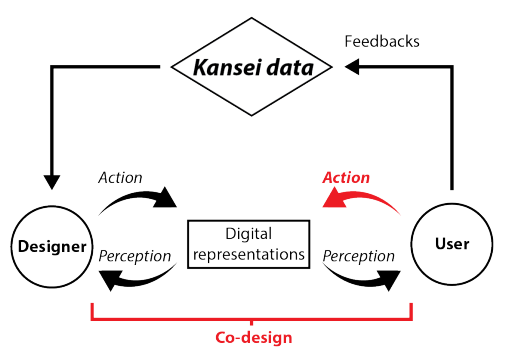

Fig. 8. Co-design between Designer and Co-design with Designer and User with the combination of MR system and kansei engineering IV [1].

The Kansei data will be generated by a mix of several techniques, listed in Table. 1. During the design process, the psychophysical state of the user is evaluated. His/her satisfaction is eventually assessed through a questionnaire. The design tool itself is also rated with the Self Assessment Manikin (SAM) method [23].

Table. 1. Items collected for creating the kansei data and the associated methods.

\begin{tabular}{ll} 
Kansei data & Assessment Method \\
\hline Usability / User Satisfaction & - Questionnaire \\
\hline Emotional reaction & - Self Assessment Manikin \\
(valence, arousal and dominance) & - Psycho-physical measurements \\
& (heart beat frequency, face expression \\
& recognition, skin conductance) \\
\hline
\end{tabular}




\subsection{Originality and expected benefits}

Our tool offers three major advantages and combines the advantages of existing methods and techniques. We build on demand the TUIs, ad-hoc to each new product development. 3D printing seamlessly integrates with CAD and has the ability to produce custom interfaces at relatively low prices. The tool offers rich interactions with touch, vision and hearing senses. TUIs can mimic real world environment and be very effective for users both experts and not experts of digital design environments, they can be effective boundary object and media of communication and collaboration. The possibility to observe and collect more accurately the expressed feelings and intentions of the participants is also increased. Tangible Augmented Reality (AR) combines the intuitiveness of TUIs with the enhanced display possibilities afforded by VR. This allows the implication of the user during the early design stages [24]. The benefits of TUIs include allowing multiple users to simultaneously view, feel and manipulate a physical shape instead of an abstract graphical representation [25]. TUIs also bridges the gap between the worlds of bits and atoms through graspable objects and ambient media in physical environment [26].

\subsection{Description of the system}

The full system we experimented is schematized in Fig. 9.

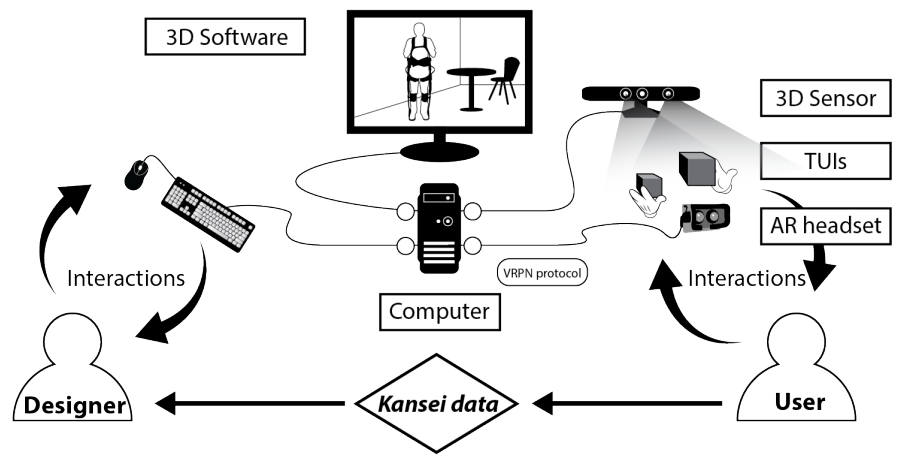

Fig. 9. Schematic description of the system.

Easy-to-use hardware.

The Oculus Rift ${ }^{\circledR}$ is a cheap head mounted display with an average price tag of USD 300. It is capable of delivering stereoscopic images using a low persistence OLED screen to eliminate motion blur and judder. Low persistence makes the scene appear visually stable, increasing the potential for presence. It is installed with an additional positional tracking and can accurately map all of the user's head movements.

We 3D print TUIs on demand for each project so they can be fitting to both the project and the user who will collaborate to the design process. The 3D printed interfaces are made from simplified shapes of the early design subcomponents of the product as recommended in kansei engineering methods. The 3D printed TUIs are produced ad-hoc to be simultaneously easy to manipulate and track. They are 
produced with a Keyence ${ }^{\circledR}$ Agilista 3100 3D printer. We use the Microsoft Kinect ${ }^{\circledR}$ for $3 \mathrm{D}$ tracking them.

\section{The software implementation offers modularity.}

Unity ${ }^{\circledR}$ is a flexible development platform for creating multiplatform $3 \mathrm{D}$ and $2 \mathrm{D}$ games and interactive experiences. We use it to connect the TUIs to the virtual objects of the 3D scene to the stereoscopic display. With Unity® software it is possible to assign to each TUIs several behaviours depending on the specific design task and the user.

\section{Conclusion}

By combining mixed reality tools and tangible user interfaces, we created a new computer-aided design system which facilitates the design collaboration between designers and users and which allows to collect user data / kansei data in the early designs stage.

Our work will now focus on implementing and testing the tool in the context of a real-life design of new WAMC. In complement of the kansei data generated by the user, the usage of the tool from the design engineers' point of view will be assessed. i.e. how useful is the user generated data and the productivity of the collaboration. The development of such a co-design digital tool is expected to help engineers designing user-friendlier products. This could enhance the quality of life for people through better user experiences with their goods.

\section{Acknowledgements}

This research has been funded by the Japan Science and Technology Agency (JST) Start-up Grant for Tenure-track Researchers, Number KH26000802.

\section{References}

1. Nagamachi, M., Lokman, A. M.: Innovations of Kansei engineering. CRC Press. (2010)

2. Metz, D. H.: Mobility of older people and their quality of life. Transport policy, 7(2), 149$152(2000)$

3. Martins, M. M., Santos, C. P., Frizera-Neto, A., Ceres, R.: Assistive mobility devices focusing on smart walkers: classification and review. Robotics and Autonomous Systems, 60(4), 548-562 (2012)

4. Farris, R. J., Quintero, H. A., Goldfarb, M.: Preliminary evaluation of a powered lower limb orthosis to aid walking in paraplegic individuals. Neural Systems and Rehabilitation Engineering, IEEE Transactions on, 19(6), 652-659 (2011)

5. Strickland, E., Good-bye, wheelchair. IEEE Spectr, 49(1), 30-32 (2012)

6. Quintero, H.A., Farris R.J., Goldfarb, M.: A method for the autonomous control of lower limb exoskeletons for persons with paraplegia, Journal of Medical Devices, 6, 1-6 (2012). 
7. Kong, K., Jeon, D.: Design and control of an exoskeleton for the elderly and patients. Mechatronics, IEEE/ASME Transactions on, 11(4), 428-432 (2006)

8. Matsuura, D., Funato, R., Ogata, M., Higuchi, M., Takeda, Y.: Efficiency improvement of walking assist machine using crutches based on gait-feasible region analysis. Mechanism and Machine Theory, 84, 126-133 (2015)

9. Higuchi, M., Ogata, M., Sato, S., \& Takeda, Y.: Development of a walking assist machine using crutches (Composition and basic experiments). Journal of mechanical science and technology, 24(1), 245-248 (2010)

10.Martin, J. L., Norris, B. J., Murphy, E., Crowe, J. A.: Medical device development: The challenge for ergonomics. Applied Ergonomics, 39(3), 271-283 (2008)

11.Nagamachi, M.: Kansei/affective engineering. CRC Press. (2010)

12.Shah, S. G. S., Robinson, I.: Benefits of and barriers to involving users in medical device technology development and evaluation. International journal of technology assessment in health care, 23(1), 131-137 (2007)

13.Carlile, Paul R.: A pragmatic view of knowledge and boundaries: Boundary objects in new product development. Organization science, 13.4, 442-455 (2002)

14.Sanders, E. B. N.: From user-centered to participatory design approaches. Design and the social sciences: Making connections, 1-8, (2002)

15.Hamade, R. F., Artail, H. A.: A study of the influence of technical attributes of beginner CAD users on their performance. Computer-Aided Design, 40(2), 262-272 (2008)

16.Sidharta, R., Olivier, J., Sannier, A., Augmented tangible interfaces for product assembly planning. International Journal of Product Lifecycle Management, 1(3), 321-331 (2006)

17.Wang, L., Shen, W., Xie, H., Neelamkavil, J., Pardasani, A.: Collaborative conceptual design - state of the art and future trends. Computer-Aided Design, 34(13), 981-996 (2002)

18.Milgram, P., Kishino, F.: A taxonomy of mixed reality visual displays. IEICE TRANSACTIONS on Information and Systems, 77(12), 1321-1329 (1994)

19.Ogi, T., Tateyama, Y., Haruyama, S.: Education on Human Centered Design Using Virtual Environment. ASME 2010 International Design Engineering Technical Conferences and Computers and Information in Engineering Conference, 667-672 (2010)

20.Arrighi, P. A., Le Masson, P., \& Weil, B.: Addressing constraints creatively: how new design software helps solve the dilemma of originality and feasibility. Creativity and Innovation Management (2014).

21.Sankai, Y.: HAL: Hybrid assistive limb based on cybernics. Robotics Research, 25-34 (2011)

22.Nagamachi, M.: Kansei engineering as a powerful consumer-oriented technology for product development. Applied ergonomics, 33(3), 289-294 (2002)

23.Bradley, M. M., \& Lang, P. J.: Measuring emotion: the self-assessment manikin and the semantic differential. Journal of behavior therapy and experimental psychiatry, 25(1), 49-59 (1994).

24.Billinghurst, M., Kato, H., Kiyokawa, K., Belcher, D., Poupyrev, I.: Experiments with faceto-face collaborative AR interfaces. Virtual Reality, 6(3), 107-121 (2002)

25.Leithinger, D., Lakatos, D., DeVincenzi, A., Blackshaw, M., Ishii, H.: Direct and gestural interaction with relief: a $2.5 \mathrm{D}$ shape display. Proceedings of the 24th annual ACM symposium on User interface software and technology, 541-548 (2011)

26.Ishii, H., Ullmer, B.: Tangible bits: towards seamless interfaces between people, bits and atoms. In Proceedings of the ACM SIGCHI Conference on Human factors in computing systems, 234-241 (1997, March) 